\title{
Silent, forgotten and
}

vulnerable: examining the risks for children with a parent in prison

by Janet Walker

By 2004, England \& Wales had become the prison capital of Western Europe and, by early 2007, the overcrowding and lack of available prison places had reached crisis proportions, attracting widespread media attention. With eight new prisons promised, the prison population seems destined to go on rising. Surprisingly, there are no accurate statistics about the number of children who experience the imprisonment of a parent, but, in 2003, the Government estimated that some 150,000 children each year in England \& Wales experience a parent being put in custody (Department for Education and Skills, (2003) Every Child Matters, Consultation paper, The Stationery Office, Cm 5860). This is the same number of children as experience the separation and/or divorce of their parents each year.

$\mathrm{T}$ here is a considerable difference between our approaches to these two groups of vulnerable children. Children of divorce are considered to be the innocent victims of their parents' decision to separate, the potentially adverse consequences are well-known, and considerable effort and resources are invested in minimising the detrimental impacts and ensuring that the best interests of children are paramount. By contrast, the children of parents who are sent to prison are a largely forgotten and neglected population. Yet having a parent in prison has been identified as a serious risk factor for children and young people: family life and parent-child relationships are severely disrupted; families are likely to be worse-off financially; children are frequently stigmatised and are less likely to do well; and new burdens are placed on Government services such as income support, housing provision, foster care and childcare (see Walker, J, and McCarthy, P, (2005) "Parents in prison: the impact on children," in G Preston (ed) At Greatest Risk: The children most likely to be poor, Child Poverty Action Group).

It is recognised by Government that low income is the most predictive indicator for signalling poor adult outcomes (see HM Treasury and Department for Education and Skills, (2007) Policy Review of Children and Young People, a discussion paper, The Stationery Office), and children with a parent in prison frequently drop into poverty. Parental imprisonment may also be a contributing factor to children becoming involved in criminal activities or antisocial behaviour themselves.

At a time when Government has attached great importance to tackling youth offending and reducing antisocial behaviour, it is worrying that more and more children are being put at risk by the imprisonment of a parent. The preventative agenda, which is to be welcomed, has yet to tackle the widespread social impacts of an ever-increasing adult prison population. While separated/ divorced parents are required to maintain their parental responsibilities irrespective of their living arrangements, there is little parents in prison can do to uphold their parental responsibilities or foster ongoing relationships with their children. The system is rarely sympathetic to their role as parents. Fathers, in particular, who are in prison have little opportunity to contribute to their children's upbringing. Yet evidence shows that fathers have a crucial role to play in the raising and well-being of children.

In a recent study of pathways into and out of crime, we sought to examine how children experience parental imprisonment and how they manage to develop resilience 
in the face of potential economic deprivation, stigma and social exclusion. We surveyed 925 prisoners in four female and four male prisons and talked in depth to: 21 prisoners (11 fathers and 10 mothers) pre- and post-release; their children aged 8-17 (38 in total); and 23 parents/carers who had looked after these children while their other parent was in prison. We found that the consequences of parental imprisonment for prisoners' families were both extensive and poorly understood. We heard stories about severe economic hardships, the difficulties in retaining parent-child relationships, multiple shifts in living arrangements, and painful social exclusion and overt stigma in local communities. Children described the multiple losses they had experienced, in a world which for them had been turned upside down, in much the same way as children of divorce talk about disruptions to family life. The consequences for both groups of children are very similar, but very few children in our prison study had received any kind of external support in dealing with them.

The scale of the impacts depends to some extent on the gender of the prisoner. When fathers go to prison the burden of childcare usually falls on mothers, who normally work hard to maintain contact with the absent parent and retain a semblance of family life, albeit as "lone" parents. By contrast, when mothers go to prison children are less likely to be cared for by their fathers and more likely to be cared for by grandparents or other family members, or to go into foster or residential care. Less than a third of children are cared for by their fathers. This lack of continuity in living arrangements is stark and problematic: it has been estimated by the Department for Education and Skills in the consultation paper previously referred to that some $55 \%$ of female prisoners have a child under 16 , with over a third of these mothers having a child under five.

There are other differences for children, depending on whether it is their mother or their father who is in prison. While children in care rarely visit a parent in prison and mothers in prison are visited less frequently than fathers, more mothers than fathers return to live with their children on release. Nevertheless, considerably more disruption is caused in the lives of children when it is their mother rather than their father who goes to prison. Furthermore, grandparents frequently have their lives turned upside down when they have to provide day-to-day care for grandchildren and manage visits to far-flung prison establishments. We spoke to several grandparents who had drained their savings to provide a stable home for their grandchildren. Often, the stress of coping with young children had had adverse impacts on the grandparents' health, which may already have been fragile. Few, if any, external support networks were available for these families.

\section{FOLLOWING IN PARENTS' FOOTSTEPS?}

It is commonly believed that criminality runs in families. Yet few of the parents in our sample had experienced the imprisonment of their own parents. Moreover, the majority of the children we talked to had not been in any kind of trouble themselves, and those who had been involved in problem behaviour were involved prior to one of their parents going to prison. Nevertheless, since parental imprisonment, boys were more likely than girls to have experienced school exclusion (29\% as against $8 \%$ ), to have got into fights with other children (29\% as against $17 \%)$, to have been in trouble with the police $(24 \%$ as against $8 \%$ ), and to have been negatively influenced by peers in terms of drinking and drug use (32\% as against 15\%). We found considerable variation between siblings, and the children who appeared to be exhibiting the most problems were those who did not visit their parents while they were in prison. Early intervention to prevent these problems escalating is essential.

Children themselves were well able to pinpoint some of the "risk factors" which impacted adversely on their lives. For example, many of the mothers in prison were serving sentences for drug-related offences, and it became clear that their children had frequently experienced chaotic lifestyles and witnessed their mothers' addiction in disturbing and dramatic ways. For some children, the imprisonment of their parent provided a welcome relief from the underworld of drugs which had permeated their lives, although when it was the mother who had gone to prison they missed the emotional closeness they valued so much. One 17-year-old girl who had begun to take heroin and had become involved in prostitution after her mother had gone to prison told us how she missed "the hugs at night time."

Many children were forced to grow up quickly, it seems, and to provide support to younger siblings, and most described an almost total lack of social support and understanding, the misery of being shunned in their neighbourhood or at school, and the need simply to survive the consequences as best they could. Many of the families felt guilty by association when a parent went to prison and had to tolerate the rejection and labelling which attached to them. This was a particular problem for children whose parents were sex-offenders.

There is no doubt that the imprisonment of a parent was generally distressing for all the children. They expressed disappointment, shock, sadness and anger. Although the majority had coped tolerably well despite a myriad of stresses and strains, repeated disruptions and difficult circumstances, some were coping less well when we talked to them. Some children appeared to be naturally resilient while others had derived significant support from family and friends. Although the criminology literature tends to portray young people's peer groups as a risk factor (and frequently they are), nevertheless, peer support and kinship networks were very important for many of the children and young people in our study. Indeed, friends were often the main providers of emotional care and support, and they it was who encouraged the maintenance of communication with an absent parent. Stability and 
security at school were also important protective factors, but frequent moves from one carer to another sometimes increased the children's vulnerability in respect of educational achievement.

\section{RETURNING HOME}

Unfortunately, circumstances do not always improve when parents are released from prison. Parents often faced considerable difficulties when they returned home: finding employment was usually difficult, managing family reintegration was not straightforward, and stigmatisation could be a continuing problem. Since prisoners are more likely than non-offenders to have low educational attainment and since over two-thirds are unemployed at the time they are sentenced (see Social Exclusion Unit (2002), Reducing Reoffending by Ex-prisoners, Office of the Deputy Prime Minister), their chances of finding work on release are minimal. This is arguably becoming even more difficult in a climate of increasing intolerance of offenders.

Social exclusion created by homelessness, worklessness and social alienation can result in the desperation which gives rise to crime. Drifting back into drug-taking and criminal behaviour seemed to some parents to be the only option open to them, causing yet more disruption in their children's lives. Over half of ex-offenders return to prison within two years (see Dibb, L (2001), "I Didn't Think Anyone Could Understand, Miss": Supporting prisoners' children in school, Federation of Prisoners' Families Support Groups). Being tough on crime can be tough for children and families. By the time we completed our research some parents were already facing a return to prison. Unless parents can be helped to find work and to reintegrate into family and community life, the revolving door is likely to leave many children with uncertain and disrupted childhoods.

\section{POLICY IMPLICATIONS}

Sadly, children whose parents are in prison receive very little support beyond that offered by family and friends. They are largely forgotten, and both silent and silenced within the community. They become guilty by association and are at greater risk of poor outcomes themselves. While children of divorced parents may feel able to confide in their friends and teachers and talk about what is happening in their lives, children with a parent in prison are naturally reluctant to admit this and may try to hide the situation. Visiting a parent in prison is itself a traumatic experience, and many of the children we spoke to had found it upsetting. Prisons are not family-friendly places, and maintaining ties with a parent in prison is expensive, sigmatising and challenging. Young people told us that they would have liked someone to talk to about what was happening in their family; they would have appreciated help with visiting their parent, access to information, and help in dealing with the practical day-to-day consequences of parental imprisonment.

If the Government is serious about eradicating child poverty, it needs to give greater attention than it currently does to the children of prisoners, who are a particularly vulnerable group. There is an urgent need for more targeted interventions for these children and their carers. The help that does exist tends to be provided by different agencies addressing different aspects of the overall problem, with little attempt to join up services and offer holistic support. A key challenge is to provide a tailored package of interventions rather than support with a single issue. But dealing with the offender becomes the main priority, and when he or she is safely locked away there appears to be little interest in the impact on and consequences for the family left behind in the community. The family may be reluctant to seek help because of the stigma attached to their situation or because they fear that if there are signs that the family is not coping the children may be taken into care. Intervening early is essential, and fits well with the Government agenda promoting a more preventative approach to children's welfare.

There is clearly a need for greater respect for children with a parent in prison, just as children whose parents separate or divorce are considered a priority group deserving sensitive support. These two groups of children experience similar disruptions and losses, yet there is little read-across of policies and approaches which could protect them. When children are given appropriate support they are better able to cope with their situation and to stay away from crime in their own lives. While having a parent in prison constitutes a risk factor for children that increases the propensity for them to get into trouble, it is important to understand how this risk is manifested and addressed. Pathways into and out of crime involve a complex interplay between risk and protective factors. The challenge is to strengthen and not undermine the social settings in which these children and young people grow up (see Homel, R, (2005) "The puzzles and paradoxes of youth crime prevention," Safer Society, NACRO). We need to question the necessity of sending so many parents to prison and, at the same time, consider the consequences of parental imprisonment for growing numbers of children and young people. 도

\section{Janet Walker}

Emeritus Professor, Newcastle Centre for Family Studies, Newcastle University. This article is taken from a paper presented by the author at the Institute of Advanced Legal Studies during a workshop on prison \& family on May 18, 2006. 